\title{
Influence of a New Diabetes Diagnosis on the Health Behaviors of the Patient's Partner
}

Julie A. Schmittdiel, $P b D^{1}$

Solveig A. Cunningham, $\mathrm{PbD}^{2}$

Sara R. Adams, MPH

Jannie Nielsen, $\mathrm{PbD}^{2,3}$

Mobammed K. Ali, $M D^{4}$

'Division of Research, Kaiser Permanente Northern California, Oakland, California

${ }^{2}$ Hubert Department of Global Health, Emory University, Atlanta, Georgia

${ }^{3}$ Global Health Section, Department of Public Health, University of Copenhagen, Denmark
Conflicts of interest: Dr Nielson reports funding from the Norvo Nordisk Foundation. The remaining authors report none.

\section{CORRESPONDING AUTHOR}

Julie A. Schmittdiel, PhD

Kaiser Permanente

2000 Broadway

Oakland, CA 94612

Julie.A.Schmittdiel@kp.org

\begin{abstract}
PURPOSE When a person is given a diagnosis of diabetes, the changes in his or her health behaviors may influence the behaviors of his or her partner. The diabetes diagnosis may affect household members' perceptions of their own health risks, which could trigger behavioral change. The purpose of this study was to assess whether partners of persons with newly diagnosed diabetes changed their health behaviors compared with partners of persons without diabetes.
\end{abstract}

METHODS The study population consisted of Kaiser Permanente Northern California health plan members from 2007 to 2011. This cohort study assessed differences in change of 8 health behaviors. The study compared coresiding partners of persons with newly diagnosed diabetes before and after a diabetes diagnosis with a 5 to 1 matched sample of coresiding partners of persons without diabetes.

RESULTS A total of 180,910 couples were included in the analysis. After adjusting for baseline characteristics, partners of persons with newly diagnosed diabetes had significantly higher rates of participation in weight management-related health education classes (risk ratio $[\mathrm{RR}]=1.50 ; 95 \% \mathrm{Cl}, 1.39-1.63$ ); smoking cessation medication use ( $R R=1.25 ; 95 \% \mathrm{Cl}, 1.05-1.50)$; glucose screening $(\mathrm{RR}=1.07 ; 95 \% \mathrm{Cl}, 1.05-1.08)$; clinically meaningful weight loss $(\mathrm{RR}=1.06 ; 95 \%$ $\mathrm{Cl}, 1.02-1.11)$; lipid screening ( $\mathrm{RR}=1.05 ; 95 \% \mathrm{Cl}, 1.04-1.07)$; influenza vaccination $(\mathrm{RR}=1.03 ; 95 \% \mathrm{Cl}, 1.02-1.04)$; and blood pressure screening $(\mathrm{RR}=1.02 ; 95 \% \mathrm{Cl}$, 1.02-1.03) compared with partners of persons without diabetes.

CONCLUSIONS There were small but significant differences in health-related behavioral changes among partners of persons with newly diagnosed diabetes compared with partners of persons without diabetes, even when no intervention occurred. This finding suggests a diabetes diagnosis within a family may be a teachable moment to improve health behaviors at the household level.

Ann Fam Med 2018;16:290-295. https://doi.org/10.1370/afm.2259.

\section{INTRODUCTION}

$\mathrm{D}$ iabetes mellitus is a chronic health condition affecting more than 29 million people in the United States. ${ }^{1}$ Diabetes can have a profoundly negative impact on quality of life and patient clinical outcomes, such as the heightened risk of microvascular and macrovascular complications, and is costly to individual persons, their families, and society at large. ${ }^{2-7}$ Optimal management of diabetes requires a complex and demanding behavioral management regimen involving the monitoring of symptoms and blood glucose levels, adherence to medications, efforts at smoking cessation when necessary, and often major changes in diet and physical activity level. ${ }^{8,9}$ Because much of this care management takes place outside the health care setting, families are often directly involved in the care of persons with diabetes. ${ }^{10}$ Providing this care and serving as a key component of a patient's social support network ${ }^{11}$ can put a considerable strain on family members. ${ }^{12}$

Spouses and partners of persons with diabetes may have an elevated risk of developing the disease themselves. ${ }^{13}$ This risk may be due to shared health behaviors, such as dietary habits, ${ }_{1}^{14}$ and exercise patterns. ${ }^{15}$ In the 
United States, when a new case of diabetes is diagnosed, it is recommended that clinicians and diabetes educators work with patients to lower their risk of future complications from the disease by helping them establish strong nutritional, exercise, and prevention habits. ${ }^{8}$

Previous studies have shown that lifestyle interventions may reduce diabetes risk ${ }^{16,17}$; however, it is unclear whether exposure to guidance and education regarding healthy behaviors geared toward patients with diabetes may also result in behavior changes in persons living with that patient. Although a survey of patients in a community-based diabetes intervention suggests that family members of a person with diabetes do have a higher level of diabetes-related knowledge, ${ }^{18}$ it is not known whether such knowledge results in behavioral change. Whether the health behaviors and health-screening behaviors of cohabiting spouses and partners of those with diabetes change when a diagnosis of diabetes is made within the household is unknown. The purpose of this study was to examine whether healthy behaviors and outcomes changed among coresiding partners of persons with diabetes in the year after the new diabetes diagnosis, compared with partners of persons without diabetes. The research hypothesis was that partners of those with newly diagnosed diabetes would increase their own health-seeking and monitoring behaviors.

\section{METHODS}

The study setting, data sources, and population have been described in detail elsewhere ${ }^{19}$ Briefly, demographic and clinical data were obtained from the administrative and electronic health records (EHRs) of Kaiser Permanente Northern California (KPNC). $\mathrm{KPNC}$ is an integrated health care delivery system with a diverse population of more than 4 million insured individuals who are broadly similar to California's overall population. Census data from 2010 were merged with members' census block of residence to estimate neighborhood socioeconomic characteristics.

The study population consisted of coresiding couples in which both partners were KPNC members who shared a health plan; couples were selected using coresiding status and shared health plan status determined from plan enrollment records. Couples in which 1 partner developed diabetes from 2007 to 2011 and the other partner did not have diabetes at that time were included in the analysis. Diabetes status was defined using the KPNC diabetes registry, a well-validated database of diabetes cases in KPNC. Persons were entered in the registry if they met 1 or more of the following criteria based on EHR data: 1 inpatient diagnosis of diabetes, 2 outpatient diagnoses of diabetes, 2 glucose test results in the diabetes range, or 1 prescription of a medication for diabetes. The earliest date of meeting the criteria was the diabetes diagnosis date.

The diabetes diagnosis date for the first partner was used as the index date for the couple. To comprise a similar comparison group, propensity score matching was performed to select 5 matched couples without a diabetes diagnosis for each couple with a diabetes diagnosis. Propensity scores were calculated using a logistic regression model and used to match newly diagnosed individuals with 5 individuals without diabetes for age, sex, race and ethnicity, body mass index (BMI), geocoded neighborhood education and annual income, KPNC service area, and number of primary care visits in the previous year. The index date for the comparison group was January 1 of the year of their match's diabetes diagnosis. Couples were excluded if either member was outside the ages of 18 to 89 years range or did not have KPNC coverage throughout the year before and the year after the index date (allowing for a 1-month gap per year).

\section{Outcomes}

The research hypothesis was that after their spouse's newly diagnosed diabetes, the partners would increase health-seeking behaviors, including both healthy lifestyle changes and health-monitoring and -testing behaviors. Health-seeking behaviors and health outcomes in the partner in the year before and after the index date were therefore examined as part of our prespecified analysis plan. Behaviors examined were fasting plasma glucose or glycated hemoglobin $\left(\mathrm{A}_{1 \mathrm{c}}\right)$ testing, lipid level testing, blood pressure testing, an influenza vaccination, use of a smoking cessation medication, tobacco-use status, whether they had participated in a weight-related health education class within the KPNC system, and whether the partners had meaningful weight loss after the index date defined as at least $5 \%$ of baseline weight in pounds. ${ }^{20}$ All outcome variables were extracted from EHR data on laboratory use, outpatient visits, vaccination records, health plan-sponsored wellness class participation, and pharmacy dispensing. Outcomes were dichotomized as binary variables for analysis.

\section{Statistical Analysis}

To compare the partners' health behaviors, the occurrence of the health-seeking behaviors and their outcomes in the follow-up period were modeled using 8 separate, adjusted, modified Poisson regression models to generate risk ratios, 1 for each outcome described above. The models were adjusted by sex, race or ethnicity, geocoded education and income level, baseline BMI category, ${ }_{1}^{21}$ number of primary care visits in the baseline year, and an indicator for presence of the 
health behavior or outcome in the baseline year; missing data were included as a separate category in the analyses. Subgroup sensitivity analyses stratifying the above models by sex, race or ethnicity, and overweight and obesity at baseline (BMI of 25 or greater, and $30 \mathrm{~kg} / \mathrm{m}^{2}$, respectively) were also performed.

All statistical analyses were performed with SAS v9. 3 software (SAS Institute). Analysis was conducted from 2014 to 2016. The institutional review boards of Kaiser Permanente Northern California and Emory University approved this study.

\section{RESULTS}

Included in the study were 30,155 couples in which 1 partner had newly diagnosed diabetes from 2007 to 2011 and 150,755 couples with no diabetes (Table 1). In 2011 , there were 236,538 patients in the diabetes reg-

Table 1. Characteristics of Persons With and Without Newly Diagnosed Diabetes and Their Partners

\begin{tabular}{|c|c|c|c|c|}
\hline Characteristic & $\begin{array}{c}\text { Persons With } \\
\text { Newly Diagnosed } \\
\text { Diabetes } \\
(n=30,155)\end{array}$ & $\begin{array}{l}\text { Persons Without Newly } \\
\text { Diagnosed Diabetes: } \\
\text { Matched Cohort } \\
(n=150,775)\end{array}$ & $\begin{array}{l}\text { Partners of Persons } \\
\text { With Newly } \\
\text { Diagnosed Diabetes } \\
(n=30,155)\end{array}$ & $\begin{array}{l}\text { Partners of Persons } \\
\text { Without Newly } \\
\text { Diagnosed Diabetes } \\
(n=150,775)\end{array}$ \\
\hline Age, mean (SD), y & $55.4(11.6)$ & $54.5(13.4)$ & $54.3(12.0)$ & $53.2(13.4)$ \\
\hline \multicolumn{5}{|l|}{ Age, \% } \\
\hline $18-44 y$ & 17.7 & 23.9 & 21.3 & 27.3 \\
\hline $45-64$ y & 61.0 & 53.7 & 59.5 & 52.8 \\
\hline $65-79$ y & 19.1 & 18.2 & 17.0 & 16.4 \\
\hline $80-89$ y & 2.2 & 4.1 & 2.2 & 3.5 \\
\hline \multicolumn{5}{|l|}{ Sex $\%$} \\
\hline Female & 37.1 & 34.6 & 62.8 & 65.4 \\
\hline Male & 62.9 & 65.4 & 37.2 & 34.6 \\
\hline \multicolumn{5}{|l|}{ Race or ethnicity, \% } \\
\hline White & 47.2 & 49.1 & 48.6 & 53.2 \\
\hline Black & 6.3 & 5.9 & 5.8 & 5.5 \\
\hline Hispanic & 19.1 & 18.8 & 17.7 & 17.1 \\
\hline Asian & 21.6 & 20.1 & 21.1 & 17.6 \\
\hline Other or unknown & 5.8 & 6.0 & 6.7 & 6.6 \\
\hline \multicolumn{5}{|l|}{$\begin{array}{l}\text { Geocoded education } \\
\text { >bachelor's degree, \% }\end{array}$} \\
\hline$<20$ & 28.3 & 27.9 & 28.2 & 27.5 \\
\hline $20-34$ & 30.7 & 30.5 & 30.5 & 30.2 \\
\hline $35-49$ & 21.8 & 21.7 & 21.6 & 21.6 \\
\hline$\geq 50$ & 19.2 & 20.0 & 19.2 & 20.0 \\
\hline Unknown & 0.0 & 0.0 & 0.6 & 0.8 \\
\hline \multicolumn{5}{|l|}{$\begin{array}{l}\text { Geocoded annual us house- } \\
\text { hold income, \% }\end{array}$} \\
\hline$<\$ 60,000$ & 28.6 & 28.2 & 28.4 & 27.9 \\
\hline$\$ 60,000-\$ 79,999$ & 26.1 & 25.8 & 26.0 & 25.6 \\
\hline$\$ 80,000-\$ 99,999$ & 20.6 & 20.4 & 20.5 & 20.2 \\
\hline$\geq \$ 100,000$ & 24.7 & 25.6 & 24.6 & 25.5 \\
\hline Unknown & 0.0 & 0.0 & 0.6 & 0.8 \\
\hline \multicolumn{5}{|l|}{ Body mass index, $\%$} \\
\hline Normal $(<25$ kg/m²) & 9.8 & 8.4 & 19.7 & 27.1 \\
\hline Overweight $\left(25-29 \mathrm{~kg} / \mathrm{m}^{2}\right)$ & 55.0 & 57.1 & 28.4 & 29.6 \\
\hline Obese $\left(\geq 30 \mathrm{~kg} / \mathrm{m}^{2}\right)$ & 28.5 & 28.9 & 30.6 & 21.9 \\
\hline Unknown & 6.7 & 5.7 & 21.2 & 21.4 \\
\hline $\begin{array}{l}\text { Primary care, visits, mean } \\
\text { (SD), No. }\end{array}$ & $3.4(3.7)$ & $3.1(4.1)$ & $2.5(3.5)$ & $2.5(3.3)$ \\
\hline \multicolumn{5}{|l|}{ No. of primary care visits, $\%$} \\
\hline 0 & 6.0 & 8.3 & 22.9 & 23.1 \\
\hline 1 & 23.8 & 27.1 & 22.9 & 23.6 \\
\hline $2-3$ & 37.7 & 36.5 & 30.7 & 30.6 \\
\hline$\geq 4$ & 32.5 & 28.1 & 23.5 & 22.8 \\
\hline
\end{tabular}

Note: Data source is Kaiser Permanente Northern California Electronic Health Records. 


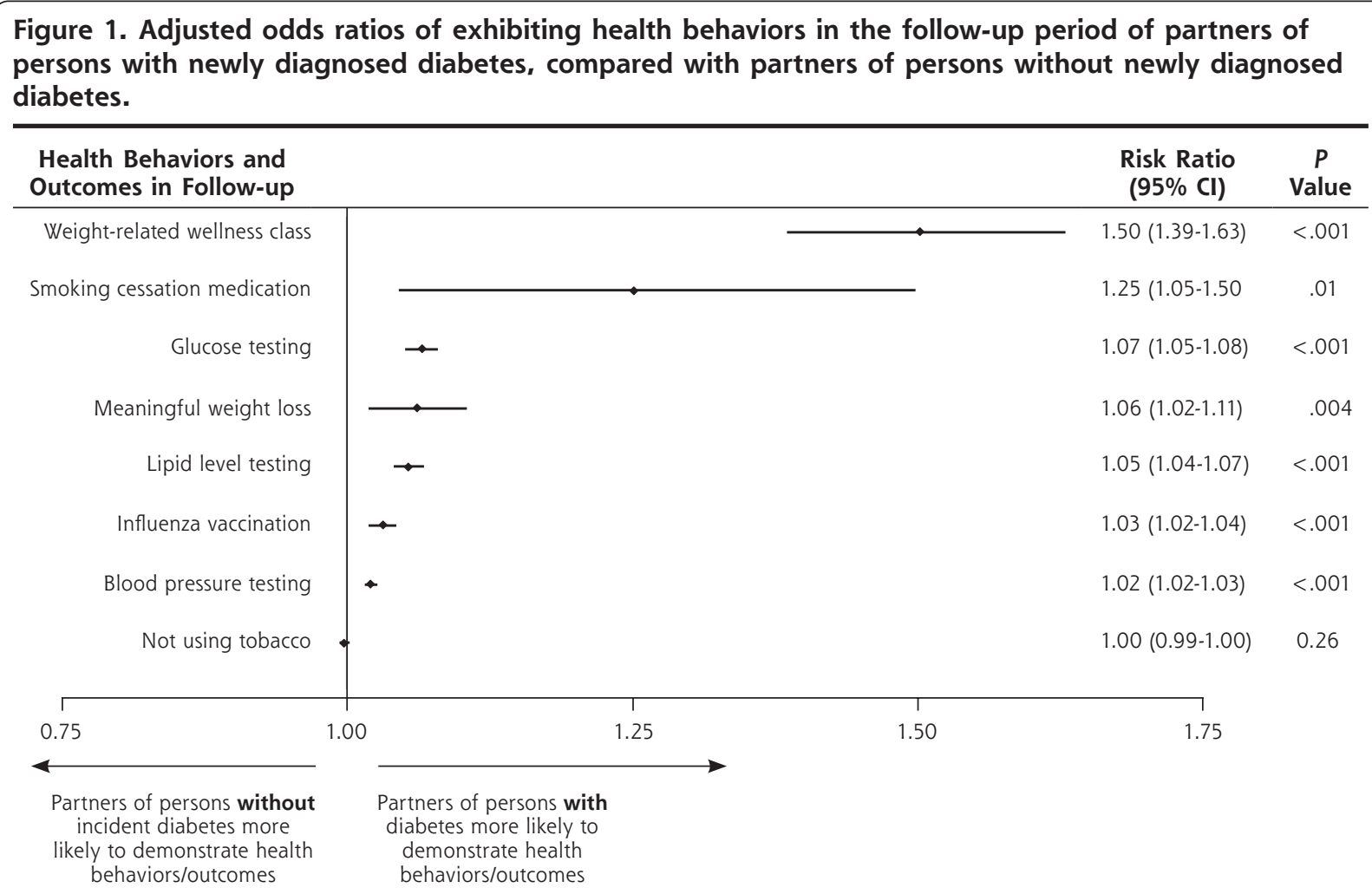

Note: Adjusted for baseline level of behavior and outcome variable, sex, race/ethnicity, geocoded education level, baseline body mass index category, and number of primary care visits.

istry overall (data not shown). The partners of persons with diabetes selected for this study had a mean age of 54.3 years ( $\mathrm{SD}=12.0$ years), and a mean BMI of 29.4 $\mathrm{kg} / \mathrm{m}^{2} ; 62.8 \%$ were female, and less than $50 \%$ were white. The control group of partners of persons without diabetes had a mean age of 53.2 years $(\mathrm{SD}=13.4$ years) and a mean BMI of $27.8 ; 65.4 \%$ were female, and 53.2\% were white.

Figure 1 displays the adjusted risk ratios and 95\% confidence intervals for exhibiting each health behavior and achieving weight loss in the follow-up period for partners of persons with newly diagnosed diabetes compared with their matched comparisons, adjusting for any differences between the 2 groups in baseline levels (also included as an indicator for the health behavior or outcome in the baseline year), BMI, number of primary care visits, sex, race or ethnicity, and geocoded education level. Partners of persons with newly diagnosed diabetes were significantly more likely to participate in weight management-related health education classes (risk ratio $[\mathrm{RR}]=1.50 ; 95 \% \mathrm{CI}$, 1.39-1.63) and to use smoking cessation medications $(\mathrm{RR}=1.25 ; 95 \% \mathrm{CI}, 1.05-1.50)$. They were also more likely to receive glucose testing $(\mathrm{RR}=1.07 ; 95 \% \mathrm{CI}$, 1.05-1.50), achieve meaningful weight loss of at least
$5 \%(\mathrm{RR}=1.06 ; 95 \% \mathrm{CI}, 1.02-1.11)$, and receive lipid screening $(\mathrm{RR}=1.05 ; 95 \% \mathrm{CI}, 1.04-1.07)$, an influenza vaccination $(\mathrm{RR}=1.03 ; 95 \% \mathrm{CI}, 1.02-1.04)$, and blood pressure screening $(\mathrm{RR}=1.02$; $95 \% \mathrm{CI}, 1.02-1.03) \mathrm{com}$ pared with partners of persons without diabetes. Sensitivity analyses stratifying by sex, race or ethnicity, and baseline weight showed similar results across categories (data not shown).

\section{DISCUSSION}

When a patient has diabetes newly diagnosed, the education and counseling they receive regarding healthy lifestyles, behavioral change, and prevention may affect the knowledge and behavior of other members of the household who are exposed to this information about diabetes risk. ${ }^{18}$ This study found that among a diverse cohort of coresiding partners of persons with newly diagnosed diabetes, these partners were more likely to exhibit health and health-monitoring behavior changes compared with partners of persons without the disease after adjusting for differences in demographic and clinical characteristics. Although transient lifestyle changes and screening behaviors may not reduce diabetes risk, an increase in both types of behaviors may 
attest to a greater attention to health status among partners of persons with diabetes.

Clinical and education interventions for diabetes and related conditions, such as obesity and cardiovascular disease, are traditionally focused primarily on the patient with a newly diagnosed case of diabetes. ${ }^{22}$ There is increasing recognition, however, that persons with diabetes benefit when family members are also involved in the lifestyle and disease management education. For example, spousal support has been shown to be linked to greater physical activity among type 2 diabetic patients, ${ }^{23}$ and family support is associated with greater achievement of weight loss goals. ${ }^{24,25}$

Despite evidence that health behaviors and lifestyle choices tend to cluster within households, ${ }_{1}^{13-15}$ very few behavioral and clinical interventions focus on changing behaviors among members of the diabetes patient's family, even though family members have been shown to also be at elevated risk of developing diabetes themselves. ${ }^{26-29}$ This study found that even in the absence of any lifestyle intervention geared toward family members, partners of persons with newly diagnosed diabetes exhibited small but significantly higher levels of behavioral changes compared with a similar set of matched control partners of persons without diabetes in the household. This finding suggests that a diabetes diagnosis may introduce a teachable moment for family members. Together, the diagnosis offers an opportunity to both reduce the risk of complications for the patient and potentially delay or prevent the development of diabetes in their partners. Future research should focus on developing and disseminating effective interventions designed to reduce health risk within families and social networks, as opposed to strictly within individuals.

This study has limitations that should be noted. Propensity score matching is unable to control for unmeasured confounders. Despite the similarities in the partners of persons with and without newly diagnosed diabetes, and that these analyses adjusted for any measured differences between the partners of the 2 groups, and it is possible that there are differences in motivation or activation that could not be measured or controlled for in the analyses. It was not possible to measure health behaviors important to reducing diabetes risk, such as physical activity levels or nutritional or caloric intake. Even so, the study takes advantage of clinical, measured EHR data for a wide range of behaviors and outcomes that do not rely on self-report. Our study included partners only when both were members of $\mathrm{KPNC}_{\text {; }}$ diabetic patients whose partners received health care from another source might exhibit different outcomes. Significant results in large observational studies such as this may not always be considered clinically important, which interventions targeting these behaviors should consider in their design. Finally, the results came from a single health delivery system serving persons in Northern California, which may limit their generalizability to persons in other types of insurance, clinical, and geographic environments.

This study showed that the partners of persons with diabetes make positive changes in health careseeking and health behaviors compared with partners of persons without diabetes. Future research should fharness this teachable moment and identify interventions that can effectively reduce overall health risks in both partners.

To read or post commentaries in response to this article, see it online at http://www.AnnFamMed.org/content/16/4/290.

Key words: diabetes mellitus, type 2 ; health education

Submitted October 28, 2017; submitted, revised, February 23, 2018; accepted March 21, 2018.

Funding support: This work is supported by grant number DK09855801 from the National Institute of Diabetes and Digestive and Kidney Diseases (NIDDK). Dr Schmittdiel is also supported by the Health Delivery Systems Center for Diabetes Translational Research (P30DK092924). Dr Ali is also supported by the Georgia Center for Diabetes Translation Research (P30DK111024).

Previous presentations: This work was presented at the European Association for the Study of Diabetes (EASD) Annual Meeting; September 12-16, 2016, Munich, Germany; and at the American Diabetes Association Scientific Sessions; June 10-14, 2016, New Orleans, Louisiana.

\section{References}

1. U.S. Department of Health and Human Services, Centers for Disease Control and Prevention. National diabetes fact sheet: national estimates and general information on diabetes and prediabetes in the United States, 2011. https://www.cdc.gov/diabetes/pubs/pdf/ ndfs_2011.pdf. Published 2011. Accessed Jul 22, 2014.

2. Fox CS, Coady S, Sorlie PD, et al. Increasing cardiovascular disease burden due to diabetes mellitus: the Framingham Heart Study. Circulation. 2007;115(12):1544-1550.

3. Franco OH, Steyerberg EW, Hu FB, Mackenbach J, Nusselder W. Associations of diabetes mellitus with total life expectancy and life expectancy with and without cardiovascular disease. Arch Intern Med. 2007;167(11):1145-1151.

4. Rodbard HW, Green AJ, Fox KM, Grandy S, Group SS; SHIELD Study Group. Impact of type 2 diabetes mellitus on prescription medication burden and out-of-pocket healthcare expenses. Diabetes Res Clin Pract. 2010;87(3):360-365.

5. American Diabetes Association. Economic costs of diabetes in the U.S. in 2007. Diabetes Care. 2008;31(3):596-615.

6. Zhang P, Brown MB, Bilik D, Ackermann RT, Li R, Herman WH. Health utility scores for people with type 2 diabetes in U.S. managed care health plans: results from Translating Research Into Action for Diabetes (TRIAD). Diabetes Care. 2012;35(11):2250-2256.

7. Dall TM, Zhang Y, Chen YJ, Quick WW, Yang WG, Fogli J. The economic burden of diabetes. Health Aff (Millwood). 2010;29(2): 297-303. 
8. American Diabetes Association. Standards of medical care in diabetes-2016: summary of revisions. Diabetes Care. 2016;39(Suppl 1):S4-S5.

9. Gonder-Frederick LA, Cox DJ, Ritterband LM. Diabetes and behavioral medicine: the second decade. J Consult Clin Psychol. 2002; 70(3):611-625.

10. Rintala TM, Jaatinen P, Paavilainen E, Astedt-Kurki P. Interrelation between adult persons with diabetes and their family: a systematic review of the literature. J Fam Nurs. 2013;19(1):3-28.

11. Keogh KM, Smith SM, White P, et al. Psychological family intervention for poorly controlled type 2 diabetes. Am J Manag Care. 2011; 17(2):105-113.

12. Fisher L, Chesla CA, Skaff MM, Mullan JT, Kanter RA. Depression and anxiety among partners of European-American and Latino patients with type 2 diabetes. Diabetes Care. 2002;25(9):1564-1570.

13. Hemminki K, Li X, Sundquist K, Sundquist J. Familial risks for type 2 diabetes in Sweden. Diabetes Care. 2010;33(2):293-297.

14. Pachucki MA, Jacques PF, Christakis NA. Social network concordance in food choice among spouses, friends, and siblings. Am J Public Health. 2011;101(11):2170-2177. 10.2105/AJPH.2011.300282.

15. Ask H, Rognmo K, Torvik FA, Røysamb E, Tambs K. Non-random mating and convergence over time for alcohol consumption, smoking, and exercise: the Nord-Trøndelag Health Study. Behav Genet. 2012;42(3):354-365.

16. Knowler WC, Fowler SE, Hamman RF, et al; Diabetes Prevention Program Research Group. 10-year follow-up of diabetes incidence and weight loss in the Diabetes Prevention Program Outcomes Study. Lancet. 2009;374(9702):1677-1686.

17. Lindström J, Ilanne-Parikka P, Peltonen $M$, et al; Finnish Diabetes Prevention Study Group. Sustained reduction in the incidence of type 2 diabetes by lifestyle intervention: follow-up of the Finnish Diabetes Prevention Study. Lancet. 2006;368(9548):1673-1679.

18. Baptiste-Roberts K, Gary TL, Beckles GL, et al. Family history of diabetes, awareness of risk factors, and health behaviors among African Americans. Am J Public Health. 2007;97(5):907-912.
19. Cunningham SA, Schmittdiel JA, Adams SR, Ali MK. Incidence of diabetes after a partner's diagnosis. Prev Med. 2017;105:52-57.

20. Stevens J, Truesdale KP, McClain JE, Cai J. The definition of weight maintenance. Int J Obes (Lond). 2006;30(3):391-399.

21. World Health Organization. Obesity: Preventing and Managing the Global Epidemic. Report of a WHO Consultation. WHO Technical Report Series no. 894. Geneva, Switzerland: World Health Organization; 2000.

22. Carey N, Courtenay M. A review of the activity and effects of nurse-led care in diabetes. J Clin Nurs. 2007;16(11C):296-304.

23. Khan CM, Stephens MA, Franks MM, Rook KS, Salem JK. Influences of spousal support and control on diabetes management through physical activity. Health Psychol. 2013;32(7):739-747.

24. Dill EJ, Manson SM, Jiang L, Pratte KA, Gutilla MJ, Knepper SL, et al; Special Diabetes Program for Indians Diabetes Prevention Demonstration Project. Psychosocial predictors of weight loss among American Indian and Alaska native participants in a diabetes prevention translational project. J Diabetes Res. 2016;2016:1546939.

25. Pinelli NR, Brown MB, Herman WH, Jaber LA. Family support is associated with success in achieving weight loss in a group lifestyle intervention for diabetes prevention in Arab Americans. Ethn Dis. 2011;21(4):480-484.

26. Hu J, Wallace DC, McCoy TP, Amirehsani KA. A family-based diabetes intervention for Hispanic adults and their family members. Diabetes Educ. 2014;40(1):48-59.

27. Myers MF, Fernandes SL, Arduser L, Hopper JL, Koehly LM. Talking about type 2 diabetes: family communication from the perspective of at-risk relatives. Diabetes Educ. 2015;41(6):716-728.

28. Nader PR, Sallis JF, Patterson TL, et al. A family approach to cardiovascular risk reduction: results from the San Diego Family Health Project. Health Educ Q. 1989;16(2):229-244.

29. Kegler MC, Alcantara I, Veluswamy JK, Haardörfer R, Hotz JA, Glanz K. Results from an intervention to improve rural home food and physical activity environments. Prog Community Health Partnersh. 2012;6(3):265-277. 